\title{
Investigate French Fries Cooking Practices in Restaurants and the Implications on Public Health in Muscat, Oman
}

\author{
Majed M AbuKhader ${ }^{1,2 *}$, Sana' Al-Ebbini ${ }^{2}$ and Rawan Abdelraziq ${ }^{\mathbf{1}}$ \\ ${ }^{1}$ Department of Pharmacy, Oman Medical College, Muscat, Oman \\ ${ }^{2}$ College of Pharmacy, National University of Science and Technology, Muscat, Oman \\ *Corresponding Author: Majed M AbuKhader, College of Pharmacy, National University of Science and Technology, Muscat, Oman. \\ E-mail: majedabukhader@nu.edu.om
}

Received: October 17, 2019; Published: November 04, 2019

DOI: 10.31080/ASNH.2019.03.0519

\begin{abstract}
The purpose of this study is to identify the frying practices such as frying time and frying temperature followed in Food Service Establishments (FSEs) in Muscat and assess the awareness of shift supervisors about the presence of acrylamide in French fries. The cooking instructions from 34 frozen pre-fried French fries products were recorded. An open-ended questionnaire was used and distributed to shift supervisors in 83 FSEs to assess the Frying practices followed in restaurants. The results showed a statistically significant $(p<0.05)$ variation in the frying practices adopted by the international and local FSEs which include frying time and frying temperature. This can be due, at least in part, to the fact that the majority of respondents did not consider the possible formation of acrylamide during frying. However, shift supervisors in international FSEs were better informed about the nature of French fries than their counterparts in the local FSEs because of the training and the follow up they have received.

In conclusion, a clear variation in frying practices followed by FSEs which would suggest a possible variation in amount and concentration of acrylamide in the French fries served in these establishments.
\end{abstract}

Keywords: Acrylamide; French Fries; Public Health; Food Service Establishments; Frying Practices

\section{Introduction}

White potatoes have been a staple food in many traditional diets of the Western world [1]. In public health point of view potatoes represent a contradictory food because they contain both macro- and micronutrients with possible beneficial and harmful effects on health. Potatoes are rich in starch and have a high glycemic index, which has been associated with an increased risk of developing obesity, diabetes, and cardiovascular disease (CVD) [2,3]. On the other hand, potatoes provide other important micronutrients including potassium, fibers, magnesium, and vitamins B6 and $\mathrm{C}$ which are all associated with a decreased risk of morbidity and mortality [4].

Frying is one of the common techniques of food preparation in households, fast food outlets and restaurants [5]. The process of frying involves oxidation, hydrolysis and polymerization, as a result of which a large group of undesirable components is produced such as acrylamide [5]. High acrylamide concentrations in food were detected first in 2002 by the Swedish National Food Administration, and the mechanism of acrylamide formation in food has been described thoroughly in the literature [6,7].

Acrylamide is formed during high-temperature processing of food rich in carbohydrates, especially potato-based products; such as French fries and potato crisps, cereal products and coffee through the process of turning brown during baking, roasting and frying [8]. This finding caused distinct concern in the scientific community; since animal experiments had shown that acrylamide is a genotoxic, neurotoxic and carcinogenic agent, and its presence in food products was considered of high risk on human health. In May 2007, the EU Commission decided to monitor the level of acrylamide in food [8]. Knowing that elimination of acrylamide from foods is virtually impossible; the objective was to reduce the amount formed in a given product. The amount of acrylamide in food depends on processing conditions, such as the temperature used in cooking and the duration of keeping food at such temperature [1]. Actually, it is the thermal input that is crucial, that is to say the combination of temperature and heating time to which the product is subjected.

The highest content of acrylamide was found in French fries and in potato chips [8]. Fried potato products, mainly French fries and potato crisps, are consumed across all age groups and socioeconomic status and provide between-the-meal snacks for many consumers all over the world [4]. Muscat is the capital city of Oman, a country located in the southeastern corner of the Arabian Peninsula. Oman is one of the developing countries in the Arabian Gulf, where the westernisation of lifestyle is associated with high consumption of fast food ( $>4$ times/week) and French fries and potato chips ( $\geq 3$ times/week) [9]. Therefore, such products are considered as a predominant source of acrylamide because they are extensively consumed [1]. 
French fries are widely prepared in restaurants which can be referred to as Food Service Establishments (FSEs) and the frying practices in these outlets are crucial; because acrylamide is formed towards the end of the frying process. Therefore, the purpose of this study was to record contents and the typical cooking instructions written on the outer package of frozen pre-fried French fries products marketed in Oman. Moreover, to identify the frying practices followed in local and international brands FSEs; in order to determine the level of knowledge among restaurant supervisors about acrylamide and their adherence to the typical frying instructions. This small-scale study is meant to give a glimpse over a possible variation in frying practices of pre-fried French fries which could have an impact on the acrylamide formation and concentration in the final product.

\section{Methods}

This study was conducted in 2018 and an ethical approval was granted by the Institutional Ethical Committee of College of Pharmacy, the National University of Science and Technology and it was designed to investigate the following:

Record the contents and cooking instructions on the pre-fried French fries products

Thirty four frozen pre-fried French fries products marketed in Muscat were selected for this study. The selection of these products based on that these products clearly mentioned on the outer package the term: 'French fries' and whether they were 'straight cut fries' or 'thin cut fries' which typically represent the standard French fries commonly served in FSEs. Other types of potato products such as curly fries and potato wedges were excluded. The information about the content and cooking instructions was found at the back side of all the selected products and in different languages.

Survey on frying practices followed in local and international brands FSEs

A cross sectional small-scale survey, based on 83 respondent FSEs; 46 local and 37 international brands restaurants (such as Burger King, McDonalds, Checking, KFC, Pizza Hut, Hardes. etc.) in Muscat, was conducted using a questionnaire designed to be simple and to achieve the purpose of this study. The selected restaurants offer French fries as single and/or part of a main dish/meal in the main menu. The survey was carried out by a direct contact with shift supervisors in these restaurants whom were given the choice to participate in the questionnaire by providing a consent form. Many of them declined to participate in the survey claiming that they cannot disclose the frying practices followed in their restaurant branch as it is confidential information. The questionnaire was composed of 19 close-ended questions/statements grouped into demographic, knowledge based- and practice based- ques- tions. Demographic questions included: gender, years of experience in the restaurant branch, level of education and nationality. Some of the knowledge based questions were: people consider French fries as essential component in any meal they buy from this restaurant branch (Agree, Neutral, disagree); French fries are rich in carbohydrates (Agree, Neutral, disagree); do you use frozen pre-fried French fries in this restaurant branch? (Agree, Neutral, disagree); there are additives and preservatives added to French fries (Agree, Neutral, disagree); acrylamide (a hazardous chemical) can form in French fries upon frying in hot oil (Agree, Neutral, disagree). Practice base questions were as follows: what type of frying oil you use? (sunflower oil, corn oil, vegetable oil, sesame oil, others); the size of French fries you are using is: $(8 \times 8 \mathrm{~mm}, 9 \times 9 \mathrm{~mm}$, 10x10mm, 11x11mm, I don't know); optimal frying temperature of the oil used to fry French fries is $\left(<170 \mathrm{C}^{\circ}, 170-175 \mathrm{C}^{\circ}, 176-180 \mathrm{C}^{\circ}\right.$, $181-190 \mathrm{C}^{\circ},>190 \mathrm{C}^{\circ}$ ); the frying time required to get crunchy golden French fries is ( $<3$ minutes, 3-5 minutes, $>5$ minutes); you learned about the optimal frying temperature and time from: (your own experience, senior staff/member in the restaurant, training when you first joined the work, others).

\section{Statistical analysis}

Statistical analysis of the results was conducted by using SPSS 19.0 package program. The knowledge about French fries and frying practices in local and international FSEs were assessed using cross tabulation analysis. The results were considered statistically significant at $\mathrm{p}<0.05$.

\section{Results}

Analysis of the data obtained from the selected pre-fried French fries products and the survey distributed to FSEs revealed the following information:

Record the contents and cooking instructions on the pre-fried French fries products

Looking into the nutrition panel of the pre-fried French fries products, the mean carbohydrate $(\mathrm{g})$ in $100 \mathrm{~g}$ was $21.3 \mathrm{~g} \pm 1.7$ and the mean amount of energy (kcal) from $100 \mathrm{~g}$ was $134.9 \mathrm{kcal} \pm 8.5$. Meanwhile, the outer package of all the products provides information about the content and the cooking instructions as summarized in Table 1.

Survey on frying practices followed in local and international brands FSEs

A general overall view of the results obtained from the participating FSEs as presented in Table 2 revealed that the education qualifications among shift supervisors are diploma or BSc or BA with equal distribution. Most of the participating shift supervisors (69.8\%) are Indians and Asians, and about 69.9\% have more than 5 years experience in the food industry. Among these restaurants 


\begin{tabular}{|c|c|c|c|c|}
\hline \multicolumn{5}{|c|}{ Pre-fried French fries $(n=34)$} \\
\hline \multicolumn{2}{|c|}{ General information } & \multicolumn{3}{|c|}{ Cooking instructions } \\
\hline Pre-frying oil & additives & Time (minutes) & Temperature $\left(\mathrm{C}^{\circ}\right)$ & Color outcome \\
\hline Sunflower oil $=10$ & $\begin{array}{c}\text { Disodium diphosphate } \\
\qquad(\mathrm{E} 450)=5\end{array}$ & 3 to $3.30=4$ & $175=27$ & golden yellow $=9$ \\
\hline Palm oil $=19$ & \multirow{7}{*}{ Not disclosed $=29$} & 3 to $4=14$ & $180=4$ & golden brown $=5$ \\
\hline \multirow[t]{6}{*}{ Vegetable oil $=5$} & & 3 to $5=3$ & $170-175=2$ & \multirow{6}{*}{ Not disclosed $=20$} \\
\hline & & 5 to $6=3$ & \multirow[t]{5}{*}{$180-190=1$} & \\
\hline & & 4 to $6=2$ & & \\
\hline & & $3=3$ & & \\
\hline & & $4=3$ & & \\
\hline & & $5=2$ & & \\
\hline
\end{tabular}

Table 1: General information including the content of the pre-fried French fries products $(n=34)$ and cooking instructions; frying time, frying temperature and color outcome of the French fries.

\begin{tabular}{|c|c|c|}
\hline Questions & Answers & Number (\%) \\
\hline \multirow[t]{2}{*}{ Restaurant type? } & International & $37(44.6)$ \\
\hline & Local & $46(55.4)$ \\
\hline \multirow[t]{3}{*}{ Years of experience in current restaurant? } & $<1$ years & $17(20.5)$ \\
\hline & $1-5$ years & $44(53.0)$ \\
\hline & $>5$ years & $22(26.5)$ \\
\hline \multirow[t]{4}{*}{ Years of experience in food Industry? } & $<1$ years & $4(4.8)$ \\
\hline & $1-5$ years & $21(25.3)$ \\
\hline & $5-10$ years & $36(43.4)$ \\
\hline & $>10$ years & $22(26.5)$ \\
\hline \multirow[t]{3}{*}{ Level of education? } & Diploma & $28(33.7)$ \\
\hline & BSc & $27(32.5)$ \\
\hline & Others (BA and MBA) & $28(33.7)$ \\
\hline \multirow[t]{5}{*}{ Nationality? } & Indian subcontinent & $29(34.9)$ \\
\hline & Asian & $29(34.9)$ \\
\hline & Arabic & $19(22.9)$ \\
\hline & Omani & $3(3.6)$ \\
\hline & Others & $3(3.6)$ \\
\hline \multirow{3}{*}{$\begin{array}{l}\text { People consider French fries as essential component in any meal } \\
\text { they buy from this restaurant branch. }\end{array}$} & Agree & $60(72.3)$ \\
\hline & Neutral & $17(20.5)$ \\
\hline & Disagree & $6(7.2)$ \\
\hline \multirow[t]{3}{*}{ French fries are rich in Carbohydrates. } & Agree & $55(66.3)$ \\
\hline & Neutral & $24(28.9)$ \\
\hline & Disagree & $4(4.8)$ \\
\hline \multirow[t]{3}{*}{ Do you use frozen pre-fried French fries in this restaurant branch? } & Agree & $56(67.5)$ \\
\hline & Neutral & $16(19.3)$ \\
\hline & Disagree & $11(13.3)$ \\
\hline \multirow[t]{3}{*}{ There are additives and preservatives added to the French fries. } & Agree & $21(25.3)$ \\
\hline & Neutral & $23(27.7)$ \\
\hline & Disagree & $39(47)$ \\
\hline \multirow{3}{*}{$\begin{array}{l}\text { Acrylamide (a hazardous chemical) can form in French fries upon } \\
\text { frying in hot oil. }\end{array}$} & Agree & $14(16.9)$ \\
\hline & Neutral & $38(45.8)$ \\
\hline & Disagree & $31(37.3)$ \\
\hline
\end{tabular}


Investigate French Fries Cooking Practices in Restaurants and the Implications on Public Health in Muscat, Oman

\begin{tabular}{|c|c|c|}
\hline What type of frying oil you use? & $\begin{array}{c}\text { Sunflower } \\
\text { Corn oil } \\
\text { Sesame oil } \\
\text { Vegetable oil } \\
\text { Other }\end{array}$ & $\begin{array}{c}48(57.8) \\
30(36.1) \\
1(1.2) \\
2(2.4) \\
2(2.4)\end{array}$ \\
\hline The size of French fries you use? & $\begin{array}{c}8 \times 8 \\
9 \times 9 \\
10 \times 10 \\
11 \times 11 \\
\text { I don't know } \\
\text { Variable }\end{array}$ & $\begin{array}{c}11(13.3) \\
14(16.9) \\
21(25.3) \\
8(9.6) \\
27(32.5) \\
2(2.4)\end{array}$ \\
\hline The optimal frying temperature of the oil used to fry French fries is: & $\begin{array}{c}<170 \\
170-175 \\
176-180 \\
181-190 \\
>190\end{array}$ & $\begin{array}{l}12(14.5) \\
15(18.1) \\
25(30.1) \\
20(24.1) \\
11(13.3)\end{array}$ \\
\hline $\begin{array}{l}\text { The frying time required to get crunchy golden } \\
\text { French fries is: }\end{array}$ & $\begin{array}{l}<3 \text { mints } \\
3-5 \text { mints } \\
>5 \text { mints }\end{array}$ & $\begin{array}{c}2(2.4) \\
57(68.7) \\
24(28.9)\end{array}$ \\
\hline You learned about optimal frying temperature and time from: & $\begin{array}{c}\text { Your own experience } \\
\text { Senior staff/member in restaurant } \\
\text { Training when first joined work } \\
\text { Others }\end{array}$ & $\begin{array}{l}11(13.3) \\
19(22.9) \\
51(61.4) \\
2(2.4)\end{array}$ \\
\hline
\end{tabular}

Table 2: The results with overall view of the collected data from 83 FSEs participated in the survey.

67.5\% use frozen pre-fried French fries, 19.3\% use either frozen pre-fried French fries or freshly prepared potato fries and $13.3 \%$ regularly use freshly prepared potato fries. When viewing the frying practices in participating restaurants, two types of frying oils are used; sunflower and corn oil, and it is clearly evident that frying temperature used in the frying process varies but the frying time (3-5 minutes) is a common time frame followed by $68.7 \%$ restaurants.

When statistical analysis performed to investigate the possible variation in the knowledge about French fries and frying practices in both local and international FSEs, the following results were obtained as shown in Table 3. There is a clear trend that shift supervisors in international FSEs are, in some knowledge aspects, better informed about the nature of French fries than their counterparts in the local FSEs. Regarding the level of respondents' knowledge about acrylamide, only $16.9 \%$ of respondents (from both local and international FSEs) declared that they consider the possible formation of Acrylamide (a hazardous chemical) in French fries upon frying in hot oil. In terms of frying practices, there are practice differences in the used frying oil, frying temperature and frying time settings. Furthermore, this gap in knowledge and difference in practices can be due to the fact that shift supervisors in international FSEs are better trained to do their work.

\section{Discussion and Conclusion}

Eating out of home is growing and has gained an important place in the habitual diet for Western countries and, preferably in the urban environments. Almost all FSEs whether local or international have French fries as an essential item in their menu and it is always children's favorite. There are many research reporting the presence of acrylamide in French fries through using analytical techniques such as GC-MS-SIM, GC-TOF-MS, LCMS $[1,10,11]$. There is a general consent that level of acrylamide content is strongly associated with and influenced by the frying practices; mainly frying temperature and time [12-14]. Moreover, several research done in France, Spain and Malaysia concluded that the content of acrylamide in French fries served in local restaurants is significantly higher than that served in international fast food chains $[1,2,11]$. Sanny., et al. (2012) investigated the variation in acrylamide content in French fries served in FSEs. The authors concluded that the variable practices, including lack of standardized frying temperature and time, of food handlers in FSEs (chain fast food vs institutional caterers) seem to contribute to the large variation of acrylamide content in the served French fries [1].

The results in this study showed that the instructions found on the package of the pre-fried French fries products clearly suggest a minimum frying time of 3 and a maximum of 6 minutes (with 3-5 


\begin{tabular}{|c|c|c|c|c|c|}
\hline \multirow{3}{*}{ Questions } & & \multicolumn{4}{|c|}{ Restaurant type } \\
\hline & & \multicolumn{2}{|c|}{ International } & \multicolumn{2}{|c|}{ Local } \\
\hline & & Count & Percentage & Count & Percentage \\
\hline \multirow{3}{*}{$\begin{array}{l}\text { Years of experience in current } \\
\text { restaurant? }\end{array}$} & $<1$ years & $0^{\mathrm{a}}$ & $0 \%$ & $17^{\mathrm{b}}$ & $37.0 \%$ \\
\hline & $1-5$ years & 22 & $59.5 \%$ & 22 & $47.8 \%$ \\
\hline & $>5$ years & $15^{\mathrm{a}}$ & $40.5 \%$ & $7^{\mathrm{b}}$ & $15.2 \%$ \\
\hline \multirow{3}{*}{$\begin{array}{l}\text { Do you use frozen pre-fried } \\
\text { French fries in this restaurant } \\
\text { branch? }\end{array}$} & Agree & $33^{a}$ & $89.2 \%$ & $23^{b}$ & $50 \%$ \\
\hline & Neutral & $1^{\mathrm{a}}$ & $2.7 \%$ & $15^{\mathrm{b}}$ & $32.6 \%$ \\
\hline & Disagree & 3 & $8.1 \%$ & 8 & $17.4 \%$ \\
\hline \multirow{3}{*}{$\begin{array}{l}\text { There are additives and } \\
\text { preservatives added to French } \\
\text { fries. }\end{array}$} & Agree & $5^{\mathrm{a}}$ & $13.5 \%$ & $16^{\mathrm{b}}$ & $34.8 \%$ \\
\hline & Neutral & 7 & $18.9 \%$ & 16 & $34.8 \%$ \\
\hline & Disagree & $25^{\mathrm{a}}$ & $67.6 \%$ & $14^{\mathrm{b}}$ & $30.4 \%$ \\
\hline \multirow{3}{*}{$\begin{array}{l}\text { Acrylamide (a hazardous chemi- } \\
\text { cal) can form in French fries upon } \\
\text { frying in hot oil. }\end{array}$} & Agree & 5 & $13.5 \%$ & 9 & $19.6 \%$ \\
\hline & Neutral & $8 a$ & $21.6 \%$ & $30^{\mathrm{b}}$ & $65.2 \%$ \\
\hline & Disagree & $24^{\mathrm{a}}$ & $64.9 \%$ & $7^{\mathrm{b}}$ & $15.2 \%$ \\
\hline \multirow[t]{6}{*}{ What type of frying oil you use? } & Olive oil & 0 & $0 \%$ & 0 & $0 \%$ \\
\hline & Sunflower & $26^{\mathrm{a}}$ & $70.3 \%$ & $22^{\mathrm{b}}$ & $47.8 \%$ \\
\hline & Corn oil & $6^{\mathrm{a}}$ & $16.2 \%$ & $24^{\mathrm{b}}$ & $52.2 \%$ \\
\hline & Sesame oil & 1 & $2.7 \%$ & 0 & $.0 \%$ \\
\hline & Vegetable oil & 2 & $5.4 \%$ & 0 & $.0 \%$ \\
\hline & Others & 2 & $5.4 \%$ & 0 & $.0 \%$ \\
\hline \multirow{5}{*}{$\begin{array}{l}\text { The optimal frying temperature } \\
\text { of the oil used to fry French fries } \\
\text { is: }\end{array}$} & $<170$ & $11^{\mathrm{a}}$ & $29.7 \%$ & $1^{\mathrm{b}}$ & $2.2 \%$ \\
\hline & $170-175$ & 9 & $24.3 \%$ & 6 & $13.0 \%$ \\
\hline & $176-180$ & 12 & $32.4 \%$ & 13 & $28.3 \%$ \\
\hline & $181-190$ & $5^{\mathrm{a}}$ & $13.5 \%$ & $15^{\mathrm{b}}$ & $32.6 \%$ \\
\hline & $>190$ & $0^{\mathrm{a}}$ & $0 \%$ & $11^{\mathrm{b}}$ & $23.9 \%$ \\
\hline \multirow{3}{*}{$\begin{array}{l}\text { The frying time required to get } \\
\text { crunchy golden French fries is: }\end{array}$} & $<3$ minutes & 2 & $5.4 \%$ & 0 & $0.0 \%$ \\
\hline & 3 - 5 minutes & $31^{\mathrm{a}}$ & $83.8 \%$ & $26^{\mathrm{b}}$ & $56.5 \%$ \\
\hline & $>5$ minutes & $4^{\mathrm{a}}$ & $10.8 \%$ & $20^{\mathrm{b}}$ & $43.5 \%$ \\
\hline
\end{tabular}

Table 3: A comparison between international and local FSEs. Questions which revealed significant statistical outcome were presented here. Statistical significance $(p<0.05)$ is represented by the different superscript letters $(a, b)$.

minutes as the average) while the frying temperature is suggested to be in the range of $170-175 \mathrm{C}^{\circ}$ (Table 1). Shift supervisors in FSEs in Muscat are in general educated (66.2\%) and $61.4 \%$ were provided training when they first joined the FSE, among whom $89.2 \%$ are working in international FSEs. Frozen pre-fried French fries products were the main choice in $67.5 \%$ of the sample restaurants and when the shift supervisor asked about the presence of additives and preservatives in the frozen French fries the response was either not sure/neutral $(27.7 \%)$ or disagree (47\%). This comes in agreement to the fact that only 5 frozen French fries products contain food additives (14.7\% - Table 1). In relation to acrylamide presence in French fries, it is clear that in all sample restaurants the shift supervisors are either not sure (45.8\%) or miss informed/ lack of awareness (47\%) and this has a clear association with the lack of consistency in the frying practices; especially frying temperature which drastically varies among all restaurants (Table 2).

When investigating the relationship between the type of restaurant and the standard frying practice suggested by the frozen pre-fries French fries products (170-175 $\mathrm{C}^{\circ}$ and 3-5 minutes), a strong correlation was observed by which international FSEs are more likely to follow the standard frying practice than local FSEs 
do. This could be due to the fact that $89.2 \%$ of the shift supervisors are trained on the standard practices that must be followed in general kitchen settings and frying of French fries in particular. The results in Table 3 could also indicate that shift supervisors follow the standard frying practice without being aware about its link with acrylamide formation in French fries and this explain the existence of slight deviation in frying temperature and time used in the international FSEs. The type of frying oil used in both types of FSEs varies; in international FSEs it is mostly sunflower oil (70.3\%) while in local restaurants it is mainly either corn oil (52.2\%) or sunflower oil (47.8\%). Meanwhile, the pre-frying oils used in the preparation of frozen pre-fried French fries are palm oil (55.9\%) and sunflower oil (29.4\%). Researchers have investigated effect of the type of frying oil on acrylamide formation in French fries as well as the effect of heat on frying oil [15-17]. Mestdagh., et al. (2005) showed that there is no effect of oil type on acrylamide concentration in French fries if frying conditions were $175 \mathrm{C}^{\circ}$ for 5 minutes. In another study done by Daniali., et al. (2016) reported that heating of the frying oil at $180 \mathrm{C}^{\circ}$ for 30 minutes would make the frying oil prone for the formation of large amount of acrylamide specially with sunflower and soybean oils.

This study highlighted the fact that there is a variation in frying practices of French fries in FSEs in general and in between international and local FSEs, which was also observed in other studies $[1,2,11]$. This has a potential impact on the quality of French fries, represented by possible high acrylamide content, served in these establishments which could pose a public health concern hence this issue requires further investigation.

\section{Future Research}

As there is no studies conducted in the Middle East region reporting and discussing the actual acrylamide content in French fries served in international and local FSEs, this pilot study is an open invitation to give this issue a priority. Furthermore, another research direction is to identify the frying practices followed in the households in Oman and the region and measure the impact of these practices on acrylamide levels in French fries. This issue has an effect on large number of population, especially children to whom French fries are always presented to them as a totally safe food item to consume.

\section{Author Disclosure Statement}

Authors declare no conflict of interest and there is no financial support for this research. It must be highlighted that human and animal subjects were not involved in any experimentation in this study. Consent was obtained from participants who took part in the survey.

\section{Bibliography}

1. Sanny M., et al. "Possible causes of variation in acrylamide concentration in French fries prepared in food service establishments: an observational study". Food Chemistry 132 (2012): 134-143.

2. Luning PM and Sanny. "Acrylamide in fried potato products". In: Gokmen V. (Ed.).Acrylamide in food: analysis, content and potential health effects. London, UK: Academic press (2016): 159-175.

3. Veronese N., et al. "Fried potato consumption is associated with elevated mortality: an 8-y longitudinal cohort study". The American Journal of Clinical Nutrition 106 (2017): 162-167.

4. Abong GO and Kabira JN. "Potential food safety concerns in fried potato products in Kenya”. OALib Journal 2 (2015): e1522.

5. Kmiecik D., et al. "The content of anti-nutritional components in frozen fried-potato products". LWT-Food Science and Technology 85 (2017): 275-282.

6. Vinci RM., et al. "Acrylamide formation in fried potato products - Present and future, a critical review on mitigation strategies". Food Chem. 133 (2012): 1138-1154.

7. U.S. Food and Drug Administration guidance for industry: Acrylamide in foods. USA: Food and Drug Administration (2016) (FDA-2013-D-0715).

8. Kowalska M., et al. "Acrylamide in food products - eating habits and consumer awareness among medical school students". Academic Emergency Medicine 24 (2017): 570-574.

9. Kilani H., et al. "Lifestyle habits: diet, physical activity and sleep duration among Omani adolescents". Sultan Qaboos University Medical Journal 13 (2013): 510-519.

10. Gokmen V., et al. "Relation between the acrylamide formation and time-temperature history of surface and core regions of French fries". Journal of Food Engineering 77 (2006): 972-976.

11. Mesias M., et al. "Acrylamide content in French fries prepared in food service establishments". LWT-Food Science and Technology 100 (2019): 83-91.

12. Romani S., et al. "Influence of frying conditions on acrylamide content and other quality characteristics of French fries". Journal of Food Composition and Analysis 22 (2009): 582-588.

13. Pedreschi F., et al. "Acrylamide content and color development in fried potato strips". Food Research International 39 (2006): 40-46. 
14. Romani S., et al. "Effect of frying time on acrylamide content and quality aspects of French fries". European Food Research and Technology 226.3 (2008): 555-560.

15. Santos C., et al. "Fried potatoes: impact of prolonged frying in monounsaturated oils". Food Chemistry 243 (2018): 192-201.

16. Mestdagh FJ., et al. "Influence of Oil Type on the Amounts of Acrylamide Generated in a Model System and in French Fries". Journal of Agricultural and Food Chemistry 53 (2005): 61706174.

17. Daniali G., et al. "Acrylamide formation in vegetable oils and animal fats during heat treatment". Food Chemistry 212 (2016): 244-249.

\section{Volume 3 Issue 12 December 2019}

(C) All rights are reserved by Majed M AbuKhader.,

et al. 